\title{
Vascular Effects of FGF-2 and VEGF-B in Rabbits with Bilateral Hind Limb Ischemia
}

\author{
Rafif Wafai Elizabeth M. Tudor James A. Angus Christine E. Wright \\ Cardiovascular Therapeutics Unit, Department of Pharmacology, The University of Melbourne, Melbourne, Vic., \\ Australia
}

\section{Key Words}

Angiogenesis - Angiography, thigh vasculature ·

Collateral artery circulation $\cdot$ Growth factors $\cdot$ Ischemia caused angiogenesis in the tibialis anterior muscle. Overall, VEGF-B may have advantages over FGF-2 in this setting; however, their combination may further improve arteriogenesis.

Copyright $\odot 2008$ S. Karger AG, Basel

\begin{abstract}
Aims: To assess fibroblast growth factor-2 (FGF-2) and vascular endothelial growth factor-B (VEGF-B) effects on flow reserve and morphological adaptation in the rabbit ischemic hind limb. Methods: Following bilateral femoral artery ligation, calf blood pressure $\left(C_{B P}\right)$, flow reserve, collateral artery numbers and capillary numbers were assessed. Treatment consisted of rabbit serum albumin (RSA), FGF-2, VEGF-B or FGF-2 + VEGF-B. Results: Ligation decreased $\mathrm{C}_{\mathrm{BP}}$; on day 14, a $48 \%$ deficit remained in the RSA group compared with a deficit of only $22 \%$ in FGF-2 and VEGF-B groups. On day 3, flow reserve was attenuated $60 \%$, but recovered by day 14 (with no treatment effects). Collateral artery numbers increased with RSA (+28\%), FGF-2 (+53\%), VEGF-B (+47\%) and FGF-2 + VEGF-B (+59\%). Rectus femoris muscle total capillary profiles and fibers per cross-section were alike across groups. Tibialis anterior muscle cross-sectional area was lower with ligation and total capillary number was less in RSA and FGF2 groups, providing evidence for angiogenesis with VEGF-B. Capillary/muscle fiber ratio was similar in each group. Conclusions: FGF-2 and VEGF-B enhanced lower limb perfusion as indicated by improved $C_{B P}$ and combined treatment increased collateral artery number. Flow reserve recovery was not enhanced by cytokine treatment. VEGF-B, but not FGF-2,
\end{abstract}

\section{Introduction}

Ischemic disease of the lower limb affects elderly patients and many are not suitable candidates for the pharmacological, reconstructive and surgical interventions that are currently available [1]. Augmentation of either arteriogenic (development and growth of collateral arteries) or angiogenic (capillary growth) processes with specific growth factors may improve perfusion to the ischemic limbs of these patients [1,2]. Many animal [3-7] and human [8-11] studies have shown an increase in vascularity and improvement in blood flow to ischemic limbs following angiogenic growth factor administration.

The angiogenic effects of vascular endothelial growth factor (VEGF)-A, which binds to both endothelial receptors VEGFR-1 and VEGFR-2, have been well documented in the literature $[1-3,12]$. However, the angiogenic potential of VEGF-B, selective for VEGFR-1, has only recently been revealed in studies in vivo $[5,13-16]$. In a mouse preparation of unilateral hind limb ischemia, Silvestre et al. [5] demonstrated that VEGF-B treatment enhanced limb perfusion, corresponding with increased arteriole

\section{KARGER}

Fax +4161306 1234 E-Mail karger@karger.ch www.karger.com

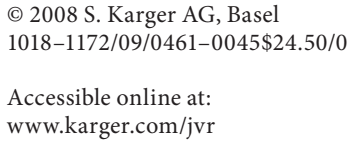

Prof. Christine E. Wright

Cardiovascular Therapeutics Unit

Department of Pharmacology, The University of Melbourne

Melbourne, Vic. 3010 (Australia)

Tel. +61 38344 8219, Fax +61 38344 0241, E-Mail cewright@unimelb.edu.au 
and capillary density, 28 days after ligation. Similarly, Wright [14] showed an improvement in calf blood pressure with VEGF-A or VEGF-B administration in the rabbit 14 days after unilateral femoral artery ligation. Fibroblast growth factor-2 (FGF-2) has potent angiogenic effects on both smooth muscle cells and endothelial cells [1]. In a rabbit model of hind limb ischemia, Baffour et al. $[4,17]$ demonstrated significant increases in collateral vessel growth and capillary density, with enhanced muscle viability, at least with low doses of FGF-2. The combination of VEGF-B and FGF-2 (not yet investigated to our knowledge) may have the potential to further enhance collateral vessel remodeling and limb perfusion, especially as FGF-2 and VEGF-A given together can synergistically increase calf blood pressure and collateral artery growth in the rabbit ischemic limb [18]. Further, the combination of FGF-2 with platelet-derived growth factor-BB augmented collateral artery growth and blood flow in a synergistic manner in both rats and rabbits [19].

Thus, the aims of the present study were to examine the effects of single and combined growth factor (FGF-2 and VEGF-B) administration on angiogenesis, arteriogenesis and flow reserve in the collateralized hindquarter vascular bed in a rabbit preparation with bilateral hind limb ischemia. A bilateral, rather than unilateral, ligation was performed to control for the possibility of 'vascular steal' - e.g., with unilateral ligation, blood may preferentially flow to the unligated limb during reactive hyperemia. Measurements of hindquarter hemodynamics, calf systolic blood pressure $\left(\mathrm{C}_{\mathrm{BP}}\right)$ and reactive hyperemia were made before and up to 14 days after bilateral or no ligation. Assessment of collateral artery and capillary numbers was done after the death of the animals on day 14 . The study shows that while VEGF-B and FGF-2 had significant effects on improving the recovery of calf blood pressure and their combined treatment increased development of collateral vessels (arteriogenesis), only VEGF$\mathrm{B}$ appeared to stimulate angiogenesis in the tibialis anterior muscle after ligation-induced ischemia.

\section{Materials and Methods}

This study was approved by the University of Melbourne in accordance with the Australian Code of Practice for the Care and Use of Animals for Scientific Purposes [ed 7; Canberra, Australian Government, National Health and Medical Research Council, 2004]. On day -10, New Zealand white rabbits underwent surgery (see below) for implantation of a flow probe and balloon cuff. Rabbits were evaluated on days 0, 3, 7, 10 and 14 after bilateral femoral artery ligation or no ligation. Hindquarter hemodynamics and reactive hyperemia (vascular reserve) were assessed.
Treatment Regimens

Treatment drugs were supplied by Zenyth Therapeutics (Melbourne, Vic., Australia). On the days specified below, the rabbits were lightly sedated with intravenous Saffan (alphaxalone/alphadolone, 6 and $2 \mathrm{mg} / \mathrm{kg}$, respectively; Pitman-Moore, Sydney, NSW, Australia) during treatments in each hind limb (i.e., bilateral). Doses were in $2 \mathrm{ml}$ phosphate-buffered saline (PBS) and divided equally into the following five muscle sites in each thigh: gracilis $(\times 2)$, semimembranosus, biceps femoris, vastus medialis and semitendinosus. The dosing regimens were similar to those used in previous work in rabbits and rats $[16,19]$.

Rabbit ligation and intramuscular treatment groups were as follows: (1) unligated: time control, PBS $2 \mathrm{ml}$ on day 1; (2) ligated: rabbit serum albumin (RSA) $500 \mu \mathrm{g}$ on day 1 and $200 \mu \mathrm{g}$ on days 3 and 5; (3) ligated: VEGF- $B_{167}$ protein $500 \mu \mathrm{g}$ on day 1 and 200 $\mu \mathrm{g}$ on days 3 and 5 ; (4) ligated: FGF-2 protein $25 \mu \mathrm{g}$ on days 1,3 and 5 , and (5) ligated: VEGF-B + FGF-2 $500+25 \mu \mathrm{g}$ on day 1 and $200+25 \mu \mathrm{g}$ on days 3 and 5 .

\section{Animal Preparation}

On day -10 the animals were anesthetized with intravenous Saffan, intubated and surgical anesthesia maintained with halothane (Rhône Mérieux, Melbourne) and $\mathrm{O}_{2}$ /air mixture. A flow probe (3 mm i.d.; Transonic Systems, Inc., Ithaca, N.Y., USA) was implanted around the lower abdominal aorta (above the aortic bifurcation) for the measurement of global hindquarter blood flow. Proximal to the probe, an inflatable balloon cuff was placed around the abdominal aorta for inducing short periods of ischemia in the hindquarter. The incision was closed and the flow probe and balloon cuff leads tunneled subcutaneously to the nape of the neck and secured externally beneath a protective upper torso jacket. Before surgery, rabbits were given the antibiotic enrofloxacin (Baytril, $5 \mathrm{mg} / \mathrm{kg}$ s.c.; Bayer Australia Ltd., Pymble, NSW, Australia; also given for 5 days after surgery) and the analgesics buprenorphine (Temgesic, $0.5 \mathrm{mg} / \mathrm{kg}$ i.v.; Reckitt \& Colman, Sydney) and carprofen (Rimadyl, $5 \mathrm{mg} / \mathrm{kg}$ i.v.; Pfizer Animal Health, Sydney; also given s.c. $24 \mathrm{~h}$ after surgery).

\section{Bilateral Femoral Artery Ligation}

On day 0 , all rabbit treatment groups, with the exception of the PBS group (which served as time control), underwent bilateral femoral artery ligation under intravenous Saffan anesthesia. After infiltration of the local anesthetic ropivacaine $\mathrm{HCl}(0.5 \%$ s.c., Naropin; AstraZeneca, North Ryde, NSW, Australia), a 5-cm longitudinal incision was made in each thigh above the femoral artery. Each femoral artery was ligated proximal to the deep femoral artery and distal to the lateral circumflex artery. Ligated animals received (doses as above) enrofloxacin (also given for 5 days after ligation), buprenorphine and carprofen (also given s.c. for 2 days after ligation).

\section{Calf Systolic Blood Pressure}

$\mathrm{C}_{\mathrm{BP}}$ was assessed on each of days 0 (just before and immediately after bilateral, or no, ligation), 3, 7, 10 and 14 . To measure $C_{B P}$ (an index of calf perfusion), rabbits were lightly sedated (just enough for immobilization) with intravenous Saffan and laser Doppler skin probes (SP300T; Oxford Optronix, Oxford, UK) were positioned over each tibial artery. Bilateral tibial artery microvascular flux was recorded and displayed on a dual-channel Oxford Array system. A soft latex cuff connected to a mercury 
manometer was placed around one calf and inflated until the tibial artery pulse as detected by the laser Doppler probe disappeared. The cuff was slowly deflated until the first reappearance of the tibial pulse flux; the manometer pressure was taken as the $\mathrm{C}_{\mathrm{BP}}$ [20]. For each limb, measurements were made in triplicate and averaged. Consistent with earlier work [21], $\mathrm{C}_{\mathrm{BP}}$ values from right and left limbs at each time point within rabbits were similar, thus the mean of right and left values was used in each case. In a pilot study in rabbits $(\mathrm{n}=3), 7$ days after femoral artery ligation (sedated as above), measurements of $\mathrm{C}_{\mathrm{BP}}$ using this cuff method $(26.7 \pm 1.2 \mathrm{~mm} \mathrm{Hg})$ were compared with mean arterial pressure (MAP) from direct saphenous artery cannulation under $0.5 \%$ ropivacaine local anesthesia $(29.0 \pm 0.6 \mathrm{~mm} \mathrm{Hg})$; these values were closely similar ( $\mathrm{p}=0.12$, paired Student's t test). Thus, the noninvasive cuff method was chosen for the serial measurements required in this study.

\section{Reactive Hyperemia Assessment}

Reactive hyperemia (flow reserve) was assessed on each of days 0 (just before ligation), 3, 7, 10 and 14. On the day of each experiment, the central ear artery was cannulated under local anesthesia ( $0.5 \%$ ropivacaine) and connected to a pressure transducer (Cobe, Lakewood, Colo., USA) for the measurement of phasic pressure and MAP. Heart rate (HR), MAP, hindquarter blood flow and hindquarter vascular resistance (HVR; MAP/blood flow) were monitored on a PowerLab data acquisition system (model 8SP; AD Instruments, Sydney). To measure reactive hyperemic responses at maximal dilatation, the aortic balloon cuff was inflated for $80 \mathrm{~s}$. Upon deflation of the balloon, a rapid increase in blood flow was observed (hyperemic response). The area under the hyperemic response curve to $100 \%$ recovery to the preocclusion baseline was calculated and the baseline flow during integration was subtracted out [flow reserve $(\mathrm{ml} / \mathrm{kg}$ body weight $)=100 \%$ recovery area - baseline flow area]. In some rabbits the balloon cuff failed and so these animals did not contribute to the hyperemia data.

\section{X-Ray Angiography}

On day 14 , after assessment of $\mathrm{C}_{\mathrm{BP}}$ and reactive hyperemia, rabbits were heparinized (100 U/kg i.v.), anesthesia induced with intravenous Saffan and deep anesthesia maintained with halothane and $\mathrm{O}_{2}$ /air mixture. Following euthanasia with pentobarbitone sodium $(120 \mathrm{mg} / \mathrm{kg}$ i.v.), the hindquarter was immediately perfused (1 liter each) via an aortic catheter at $100 \mathrm{~mm} \mathrm{Hg}$ with papaverine solution ( $3.84 \mathrm{mg} / \mathrm{l}$ saline) followed by $4 \%$ formalin in PBS. Warm red lead gelatine mix (8 g lead oxide fine powder + 1.5 g gelatine in $10 \mathrm{ml}$ water) $[14,20,22]$ was then injected into the abdominal aorta and allowed to set before angiography. Angiograms were taken with an Optimus general X-ray unit (Philips, Eindhoven, The Netherlands): focal spot size $0.6 \mathrm{~mm}, 40 \mathrm{kVp}, 160$ $\mathrm{mA}$ and exposure time $0.8 \mathrm{~s}$. In a 'blinded' manner (i.e., the identity of the rabbit treatment group was masked), arteriogenesis in each thigh evident in angiograms was quantitated using a microscope by counting the number of angiographically visible medium-large collateral vessels $(300-800 \mu \mathrm{m}$ i.d.) with clear origins proximal to the ligation and clear distal reentry [21, 23]. Measurements from each thigh were then averaged to give one value per rabbit. One angiogram with a poor fill was excluded from the data for the FGF-2 + VEGF-B group.

FGF-2 and VEGF-B in Rabbits with

Bilateral Hind Limb Ischemia

\section{Capillary Number Assessment}

A lower limb muscle (tibialis anterior) and a thigh muscle that did not receive treatment injections (rectus femoris) were chosen for assessment. Samples were obtained consistently from the same region of the muscle in the following manner: entire muscles were dissected from the origin to their point of insertion and then transected at a consistent percent distance from their point of insertion. A transverse slice ( $\sim 3 \mathrm{~mm}$ wide) was taken, embedded in paraffin, and $5-\mu \mathrm{m}$ sections were cut, mounted on glass slides, stained with hematoxylin and eosin and examined using an Olympus BX51 microscope and a DP70 camera. Muscle crosssectional areas were measured using image software (SigmaScan Pro 4; Jandel Scientific, San Rafael, Calif., USA) and then, using a fractionator method $[24,25]$ with a test grid of 24 points over an unbiased counting frame $\left(196 \times 139 \mu \mathrm{m}=27,244 \mu \mathrm{m}^{2}\right)$, total capillary profiles and muscle fiber profiles per muscle sample were estimated using a $\times 40$ objective lens. Poorly fixed muscles were excluded from the analysis.

\section{Statistical Analysis}

Data are presented as mean \pm 1 SEM. The average SEM within animals for each parameter (fig. 1,2) was calculated from repeated-measures analysis of variance (RM ANOVA) using the pooled estimate of error from the residual mean square as (error mean square/number of animals) ${ }^{0.5}$ after subtracting the sum of squares 'between animals' and 'between days' from the 'total' sum of squares for each variable [26]. $\mathrm{C}_{\mathrm{BP}}$, body weight, hemodynamics and flow reserve on days $0-14$ were compared within and between groups by RM ANOVA, with Greenhouse-Geisser correction for correlation [27] calculated by means of the statistical program SuperANOVA 1.11 for Macintosh. Within-day data (e.g., collateral vessel number, capillary number/muscle cross-section and capillary/muscle fiber ratio) were compared between treatment groups by one-way ANOVA with post hoc test for multiple comparisons where appropriate. $\mathrm{p}<0.05$ was taken as statistically significant.

\section{Results}

\section{Baseline Variables}

Rabbits in all treatment groups had a similar starting body weight of $2.7 \pm 0.1 \mathrm{~kg}$ on day $-10(\mathrm{n}=37$; $\mathrm{p}>0.05$, one-way ANOVA) and weights were comparable over the 14-day period. Four animals (3 from the RSA group and 1 from the VEGF-B group) were excluded from the hemodynamic measurements due to unsatisfactory flow probes. On day 0 (before ligation), rabbit treatment groups had similar resting HR, MAP and HVR; values were consistent over the 14-day period in all groups $(n=33 ; \mathrm{p}>0.05$, RM ANOVA; table 1) with the following exceptions: (1) MAP was significantly higher on day 3 after ligation in the FGF-2 ( $\mathrm{p}=0.006 ; \mathrm{n}=8)$ and VEGF-B + FGF-2 ( $\mathrm{p}=0.0001$; $\mathrm{n}=8$ ) groups compared to respective day 0 preligation values and (2) HVR was raised on day 3 after ligation in the FGF-2 group ( $\mathrm{p}=0.019$ compared to day 0 values). 


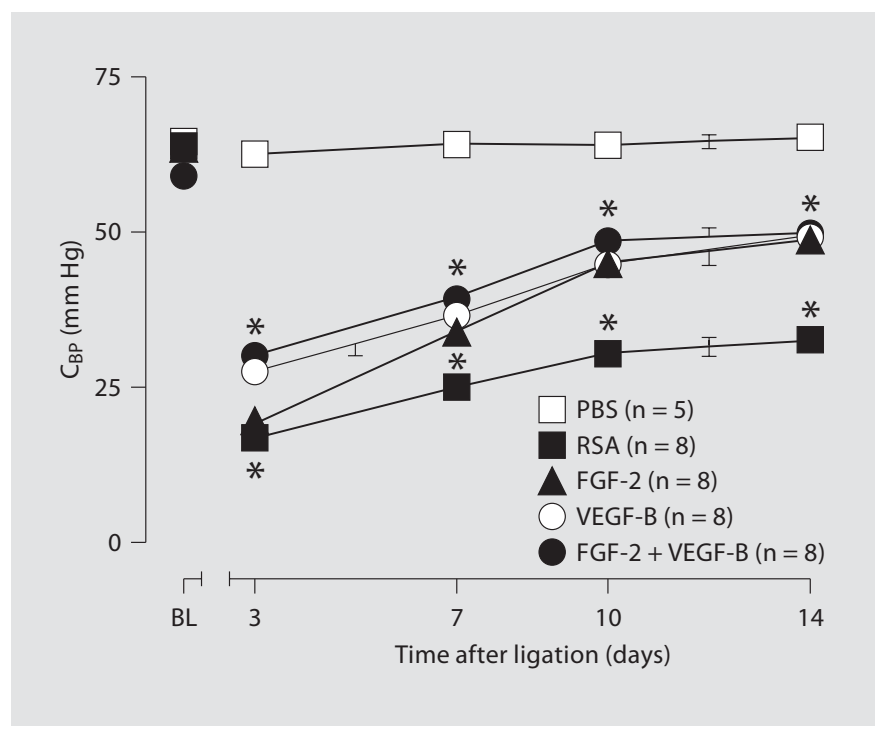

Fig. 1. $\mathrm{C}_{\mathrm{BP}}$ (mean of right and left leg) in unligated PBS-treated rabbits and ligated rabbits treated with RSA, FGF-2, VEGF-B or FGF-2 + VEGF-B at baseline (BL) before ligation (if applicable) on day 0 and 3, 7, 10 and 14 days after bilateral ligation (or no ligation). Error bars at BL are \pm 1 SEM (those not shown are contained within the symbol), and on lines average SEM from RM ANOVA are shown. ${ }^{*} \mathrm{p}<0.05$ compared to respective ligated group at $\mathrm{BL}$ (RM ANOVA).

\section{Calf Systolic Blood Pressure}

All rabbit treatment groups had similar $\mathrm{C}_{\mathrm{BP}}$ values (mm Hg) on day 0 (PBS: $64 \pm 2, \mathrm{n}=5$; RSA: $63 \pm 1$, $\mathrm{n}=8$; FGF-2: $61 \pm 2, \mathrm{n}=8$; VEGF-B: $59 \pm 2, \mathrm{n}=8$; FGF-2 + VEGF-B: $59 \pm 2, \mathrm{n}=8$; fig. 1). Bilateral femoral artery ligation caused an immediate fall in $\mathrm{C}_{\mathrm{BP}}$ to undetectable levels $(0-5 \mathrm{~mm} \mathrm{Hg}, \mathrm{n}=32)$. By day $3, \mathrm{C}_{\mathrm{BP}}$ values $(\mathrm{mm} \mathrm{Hg})$ had increased in all ligated rabbits; however, they were significantly lower in the FGF-2 (19 \pm 3$)$ and RSA (17 \pm 2$)$ groups compared with the VEGF-B $(27 \pm$ $3)$ and FGF- 2 + VEGF-B $(30 \pm 1)$ groups $(\mathrm{p}<0.0001$, one-way ANOVA; fig. 1). Over the next 11 days $\mathrm{C}_{\mathrm{BP}}$ increased in all ligated groups; however, on day 14 RSAtreated rabbits had significantly lower $\mathrm{C}_{\mathrm{BP}}$ values compared with the other treatment groups $(\mathrm{p}<0.05, \mathrm{RM}$ ANOVA; table 2), with a $48 \%$ deficit compared to baseline values. Growth factor administration (FGF-2 or VEGF-B) caused a further $26 \%$ improvement in $\mathrm{C}_{\mathrm{BP}}$ by day 14 compared with the RSA group, with only a $22 \%$ deficit remaining from baseline values. $\mathrm{C}_{\mathrm{BP}}$ was consistent over the 14-day period in the unligated PBS-treated animals ( $\mathrm{p}>0.05$, RM ANOVA).

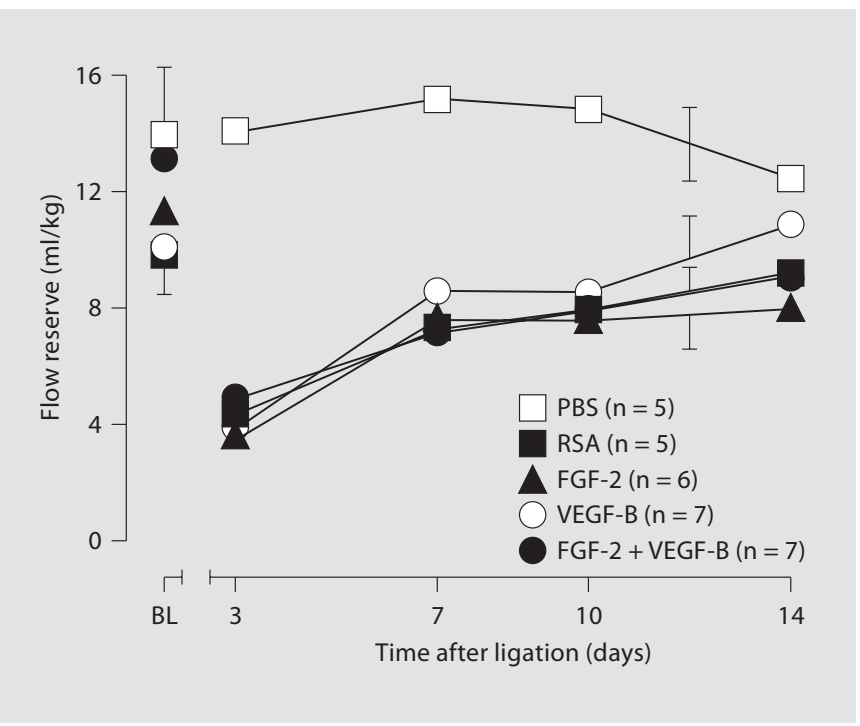

Fig. 2. Hindquarter reactive hyperemic responses [flow reserve; area under the flow-response curve $(\mathrm{ml})$ corrected for body weight $(\mathrm{kg})$ ] after aortic occlusion for $80 \mathrm{~s}$ in unligated PBS-treated and ligated rabbits treated with RSA, FGF-2, VEGF-B and FGF-2 + VEGF-B at baseline (BL) before ligation (if applicable) on day 0 and 3, 7, 10 and 14 days after bilateral ligation (or no ligation). Error bars at $\mathrm{BL}$ are $\pm 1 \mathrm{SEM}$, and on lines average SEM from RM ANOVA are shown (overlapping bars are not shown for clarity).

\section{Reactive Hyperemia}

Following aortic occlusion for $80 \mathrm{~s}$, flow reserve on day 0 (before ligation) was similar in all rabbit groups $(\mathrm{p}>$ 0.05 ; fig. 2). Values were consistent over the 14 -day period in the unligated PBS-treated group ( $\mathrm{p}>0.05)$. On day 3 after ligation, significant attenuations in flow reserve were observed, with values approximately $40 \%$ in ligated rabbits treated with RSA, FGF-2, VEGF-B or FGF-2 + VEGF-B compared to matched day 0 values ( $\mathrm{p}=0.0001$, RM ANOVA; fig. 2). Flow reserve increased slowly over the next 11 days and was not significantly different on day 14 to preligation values in each ligated group $(\mathrm{p}>0.05$, RM ANOVA; table 2).

\section{X-Ray Angiography}

Bilateral femoral artery ligation led to remodeling of vessels into corkscrew-like collateral arteries (e.g., fig. 3). The hind limbs of nonischemic rabbits (i.e., with intact femoral arteries) revealed very few visible collateral vessels. Compared to the PBS unligated group, there were significant increases in the number of angiographically visible medium-large (300-800 $\mu \mathrm{m}$ i.d.) collateral arteries in ligated rabbits treated with RSA $(+28 \%, \mathrm{n}=8)$, FGF- 
Table 1. Hemodynamics in unligated and ligated rabbits over the 14-day experimental period

\begin{tabular}{|c|c|c|c|c|c|}
\hline \multirow[t]{2}{*}{ Treatment group } & \multicolumn{5}{|l|}{ Day } \\
\hline & 0 & 3 & 7 & 10 & 14 \\
\hline \multicolumn{6}{|l|}{ Unligated PBS $(\mathrm{n}=5)$} \\
\hline $\mathrm{HR}$, beats/min & $213 \pm 6$ & $218 \pm 9$ & $208 \pm 4$ & $211 \pm 8$ & $212 \pm 7$ \\
\hline $\mathrm{MAP}, \mathrm{mm} \mathrm{Hg}$ & $68 \pm 1$ & $70 \pm 4$ & $70 \pm 3$ & $73 \pm 3$ & $69 \pm 4$ \\
\hline $\mathrm{HVR}, \mathrm{mm} \mathrm{Hg} / \mathrm{ml} / \mathrm{min} / \mathrm{kg}$ & $2.5 \pm 0.1$ & $2.9 \pm 0.2$ & $3.0 \pm 0.3$ & $3.1 \pm 0.3$ & $3.2 \pm 0.2$ \\
\hline \multicolumn{6}{|l|}{ Ligated RSA $(\mathrm{n}=5)$} \\
\hline $\mathrm{HR}$, beats/min & $227 \pm 4$ & $231 \pm 13$ & $226 \pm 18$ & $229 \pm 18$ & $219 \pm 15$ \\
\hline $\mathrm{MAP}, \mathrm{mm} \mathrm{Hg}$ & $69 \pm 1$ & $74 \pm 4$ & $70 \pm 4$ & $70 \pm 4$ & $71 \pm 2$ \\
\hline $\mathrm{HVR}, \mathrm{mm} \mathrm{Hg} / \mathrm{ml} / \mathrm{min} / \mathrm{kg}$ & $2.5 \pm 0.1$ & $3.4 \pm 0.3$ & $3.0 \pm 0.3$ & $3.0 \pm 0.3$ & $3.4 \pm 0.4$ \\
\hline \multicolumn{6}{|l|}{ Ligated FGF-2 $(n=8)$} \\
\hline $\mathrm{HR}$, beats/min & $223 \pm 8$ & $241 \pm 7$ & $237 \pm 11$ & $235 \pm 10$ & $225 \pm 12$ \\
\hline MAP, mm Hg & $72 \pm 2$ & $81 \pm 2^{*}$ & $72 \pm 3$ & $70 \pm 3$ & $71 \pm 3$ \\
\hline $\mathrm{HVR}, \mathrm{mm} \mathrm{Hg} / \mathrm{ml} / \mathrm{min} / \mathrm{kg}$ & $3.1 \pm 0.1$ & $3.6 \pm 0.2^{*}$ & $2.8 \pm 0.2$ & $3.0 \pm 0.2$ & $3.0 \pm 0.2$ \\
\hline \multicolumn{6}{|l|}{ Ligated VEGF-B $(n=7)$} \\
\hline $\mathrm{HR}$, beats/min & $213 \pm 4$ & $224 \pm 9$ & $221 \pm 6$ & $213 \pm 9$ & $214 \pm 9$ \\
\hline $\mathrm{MAP}, \mathrm{mm} \mathrm{Hg}$ & $67 \pm 2$ & $72 \pm 2$ & $73 \pm 2$ & $67 \pm 3$ & $69 \pm 2$ \\
\hline $\mathrm{HVR}, \mathrm{mm} \mathrm{Hg} / \mathrm{ml} / \mathrm{min} / \mathrm{kg}$ & $3.0 \pm 0.4$ & $3.3 \pm 0.3$ & $3.1 \pm 0.3$ & $2.6 \pm 0.2$ & $2.8 \pm 0.2$ \\
\hline \multicolumn{6}{|l|}{ Ligated VEGF-B + FGF-2 $(\mathrm{n}=8)$} \\
\hline $\mathrm{HR}$, beats/min & $213 \pm 8$ & $232 \pm 13$ & $229 \pm 7$ & $228 \pm 12$ & $228 \pm 13$ \\
\hline MAP, $\mathrm{mm} \mathrm{Hg}$ & $65 \pm 2$ & $77 \pm 3^{*}$ & $70 \pm 2$ & $70 \pm 2$ & $69 \pm 3$ \\
\hline $\mathrm{HVR}, \mathrm{mm} \mathrm{Hg} / \mathrm{ml} / \mathrm{min} / \mathrm{kg}$ & $2.9 \pm 0.3$ & $3.6 \pm 0.4$ & $3.3 \pm 0.4$ & $3.5 \pm 0.3$ & $3.4 \pm 0.3$ \\
\hline
\end{tabular}

HR, MAP and HVR (corrected for body weight) in conscious rabbits on day 0 (before ligation) and 3, 7, 10 and 14 days after either no ligation (unligated) or bilateral femoral artery ligation (ligated). Values are mean \pm 1 SEM.

${ }^{*} \mathrm{p}<0.05$ compared to within respective group on baseline day 0 (RM ANOVA).

$2(+53 \%, \mathrm{n}=8)$, VEGF-B $(+47 \%, \mathrm{n}=8)$ and FGF- $2+$ VEGF-B $(+59 \%, \mathrm{n}=7)(\mathrm{p}<0.05$, one-way ANOVA; fig. 4$)$. FGF-2 + VEGF-B coadministration also resulted in a significantly greater number of collateral arteries than in the ligated RSA-treated rabbits $(\mathrm{p}<0.05)$. This result emphasizes a significant additional effect with the combined treatment (table 2).

\section{Capillary Numbers}

There was a significant and similar decrease in the cross-sectional area in the tibialis anterior muscle in each ligated group compared to the unligated group (average $-26 \%$; $<<0.05$, one-way ANOVA; fig. 5). There were no differences in rectus femoris muscle cross-sectional areas between groups irrespective of ligation or treatment. There was a $\sim 30 \%$ fall in total capillary number per tibialis anterior muscle cross-section in RSA- or FGF-2treated ligated rabbits compared to the unligated group $(\mathrm{p}<0.01)$, with a similar (but not significant) trend in the rectus femoris muscle. In the tibialis anterior muscle, there was also a decrease in total muscle fiber number per
Table 2. Qualitative summary of the cytokine treatment effects on calf blood pressure $\left(\mathrm{C}_{\mathrm{BP}}\right)$, maximum response to acute ischemia (flow reserve) and collateral artery and capillary numbers on day 14 after femoral artery ligation

\begin{tabular}{llll}
\hline Measure & FGF-2 & VEGF-B & FGF-2 + \\
& & & VEGF-B \\
\hline $\mathrm{C}_{\mathrm{BP}}$ & + & + & + \\
$\begin{array}{l}\text { Flow reserve } \\
\begin{array}{l}\text { Arteriogenesis - } \\
\quad \text { collateral artery number }\end{array}\end{array}$ & 0 & 0 & 0 \\
$\begin{array}{l}\text { Angiogenesis - capillary number } \\
\quad \text { (tibialis anterior muscle) }\end{array}$ & 0 & 0 & + \\
\hline
\end{tabular}

$+=$ Significant effect of the cytokine(s) compared with ligated rabbits treated with RSA; 0 = no significant detectable cytokine effect compared with ligated rabbits treated with RSA. 

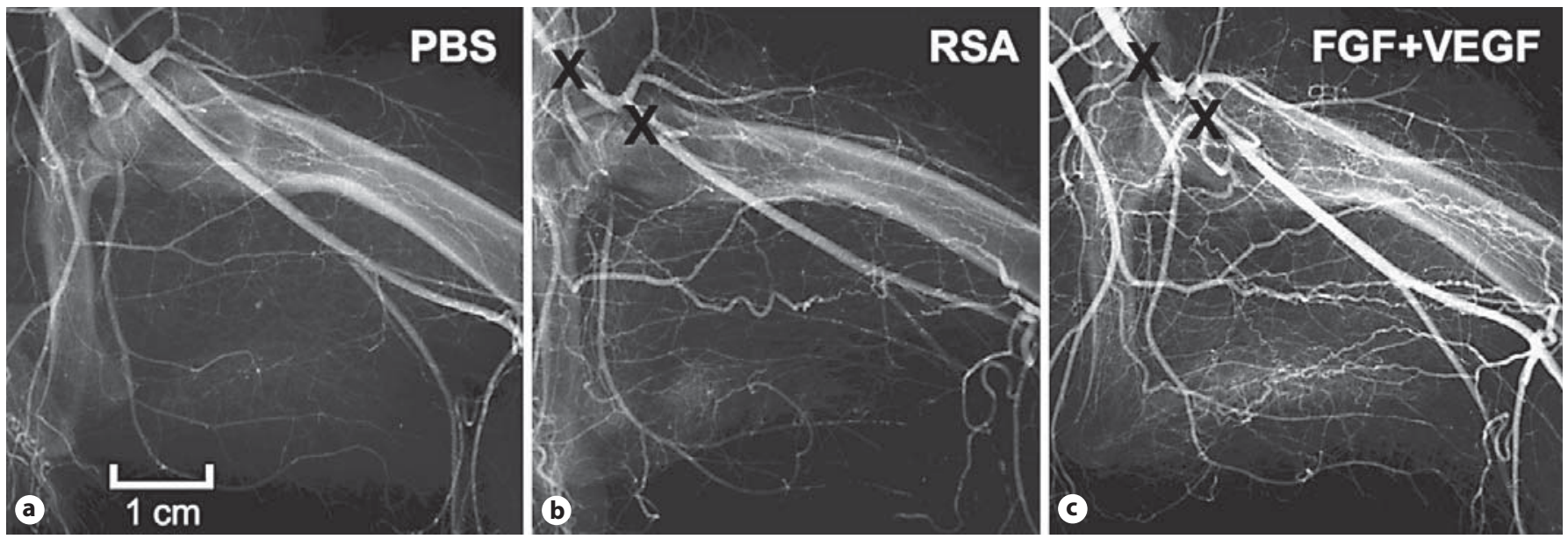

Fig. 3. Postmortem angiograms of rabbit left-thigh vasculature on day 14 in an unligated PBS-treated rabbit (a), in a ligated RSA-treated rabbit (b) and in an FGF-2 + VEGF-B-treated rabbit (c). X = Ligation points (b, c).

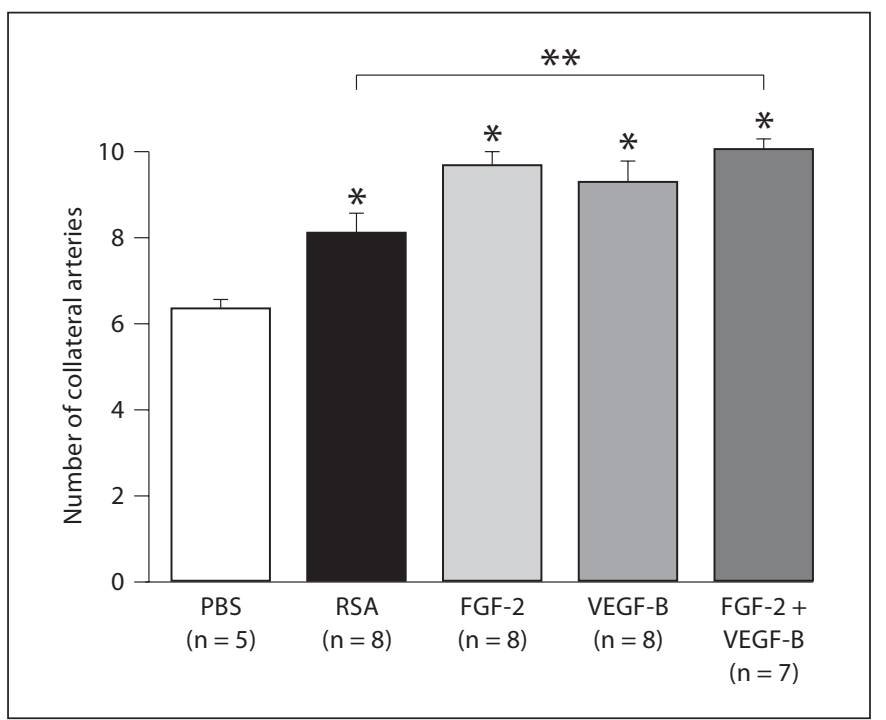

Fig. 4. Number of angiographically visible hind limb collateral arteries in unligated PBS-treated rabbits and ligated rabbits treated with RSA, FGF-2, VEGF-B and FGF-2 + VEGF-B measured from angiograms obtained on day 14 . Values from right and left legs have been averaged. Error bars are \pm 1 SEM. ${ }^{*} p<0.05$ compared to unligated PBS group; ${ }^{* *} \mathrm{p}<0.05$ ligated FGF-2 + VEGF$\mathrm{B}$ group compared to ligated RSA group (one-way ANOVA).

cross-section in the RSA and FGF-2 groups compared to the unligated PBS group ( $p<0.05$, one-way ANOVA; fig. 5); rectus femoris muscle fiber numbers were similar in all groups. In the VEGF-B groups, with/without FGF2 , both capillary number and muscle fiber number per muscle cross-sectional area were not significantly decreased compared to the PBS unligated group, suggesting that angiogenesis had restored the deficit compared with that seen in the ligated RSA and FGF-2 groups after 14 days (table 2). Capillary number/muscle fiber ratios were not significantly different between treatment groups for either muscle type ( $p>0.05$, one-way ANOVA; fig. 5).

\section{Discussion}

Our relatively severe model of hindquarter ischemia caused acute (day 3 ) loss of vascular function with large falls in $\mathrm{C}_{\mathrm{BP}}$ and flow reserve (60\% loss). By day 14 , the flow reserve was restored to preligation levels, but the $\mathrm{C}_{\mathrm{BP}}$ was still $48 \%$ in deficit. Morphology revealed a marked stimulation of collateral arteries in the ligated hindquarter and a significant $30 \%$ decrease in density of capillaries and muscle fibers in the tibialis anterior muscle on day 14 . This bilateral femoral ligation technique thus presented a useful preparation to test the effects of FGF-2 and VEGF$\mathrm{B}$ alone and in combination (table 2). We found that intramuscular FGF-2 treatment only showed a significant effect on further improving $\mathrm{C}_{\mathrm{BP}}$, while VEGF-B significantly improved $\mathrm{C}_{\mathrm{BP}}$ and capillary number (angiogenesis). When the two proteins were combined, we could not demonstrate an additive or synergistic effect on $\mathrm{C}_{\mathrm{BP}}(22 \%$ deficit still remaining) or capillary number, but there was a significant additional enhancement of arteriogenesis (collateral artery number) compared to when stimulated by ligation alone. Thus, we conclude that VEGF-B is mar- 


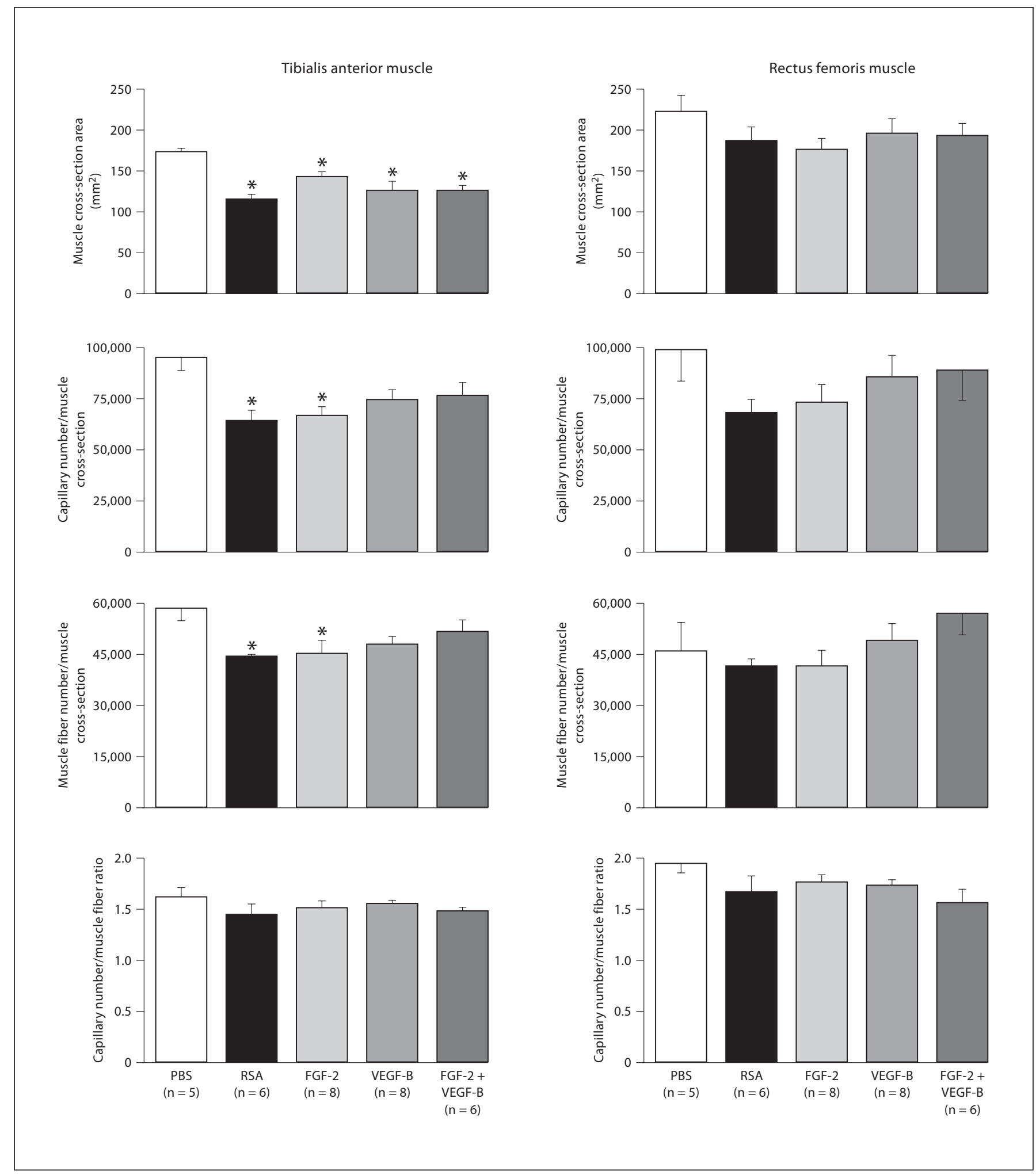

Fig. 5. Muscle cross-section area, capillary number per cross-section, muscle fiber number per cross-section and capillary number/muscle fiber ratio in tibialis anterior (left panels) and rectus femoris (right panels) muscles from unligated PBS-treated rabbits and ligated rabbits treated with RSA, FGF-2, VEGF-B and FGF-2 + VEGF-B on day 14 after ligation. Error bars are \pm 1 SEM. ${ }^{*} p<$ 0.05 with respect to the unligated PBS group (one-way ANOVA). 
ginally more effective than FGF-2 in enhancing angiogenesis but the combination may offer synergy in stimulating arteriogenesis (collateral artery development).

Major vessel occlusion is usually accompanied by compensatory vessel growth, via arteriogenesis and angiogenesis, which aids in restoring perfusion to the ischemic region. VEGF-A and FGF-2 promote angiogenesis via endothelial cell stimulation and hypoxia upregulates expression of VEGF-A and its receptors, VEGFR-1 and VEGFR-2 [1, 17, 28]. However, VEGF-B is not regulated by hypoxia [29]. FGF-2 also has a stimulatory role in arteriogenesis due to its effects on vascular smooth muscle cells in addition to endothelial cells $[28,30]$. Evidence of an enhanced perfusion to the distal hind limb was obtained from $\mathrm{C}_{\mathrm{BP}}$ measurement. Interestingly, in VEGF-Band FGF-2 + VEGF-B-treated rabbits $\mathrm{C}_{\mathrm{BP}}$ had recovered to a greater extent than in FGF-2- or RSA-treated rabbits 3 days after ligation. In the first 5 days after ligation there is increased VEGFR-1 expression $[1,30]$ and marked upregulation of FGFR-1 as early as 3-6 h (returning to control levels by days 3-7) [31] after femoral artery ligation in the rabbit. Thus, the lower $\mathrm{C}_{\mathrm{BP}}$ measurement observed with FGF-2 on day 3 in our study may have been the result of limited FGFR-1 availability. The improvement in the $\mathrm{C}_{\mathrm{BP}}$ response by day 14 with growth factor therapy alone, or in combination, correlated with the trend for increased collateral artery number with single treatments and significantly greater collateral artery number with combined cytokine treatment observed in the upper thigh. These arteries presumably would have allowed increased blood flow to the lower limb consistent with other studies $[32,33]$. The $22 \%$ deficit in $\mathrm{C}_{\mathrm{BP}}$ still present by day $14 \mathrm{de}-$ spite cytokine treatment may suggest a need to investigate an extended treatment period to examine whether this parameter of ischemia may be further restored. Allen et al. [34] infused FGF-2 intra-arterially for 14, 28 and 42 days into rat ischemic hind limbs and showed higher collateral artery-dependent blood flow after 28 days compared with 14 days, but there was no further effect after 42 days. In a previous study [21], we have shown that $C_{B P}$ continues to return towards unligated levels but by 28 days there was still a $32 \%$ deficit in rabbits not given any treatment.

Vascular flow reserve was markedly decreased by $60 \%$ when assessed 3 days after ligation in this study. This response slowly improved by day 14 , with or without exogenous growth factor administration, to values not significantly different from preligation baselines. Despite the enhancement of collateral arterial growth noted in the ligated rabbits treated with VEGF-B and FGF-2 at day
14, this was not reflected in an earlier improvement at days 7 and 10 in hindquarter flow reserve. In contrast, Wright [14] found a preservation in flow reserve at 14 days with VEGF-B gene transfer treatment (500 $\mu \mathrm{g}$ i.m., day 1 after ligation). FGF-2 increased collateral arterydependent blood flow at 7 days with marked synergy when combined with platelet-derived growth factor (PDGF-BB) [19] in rabbits with unilateral femoral artery ligation. The reasons for the lack of effect of cytokine treatment on flow reserve in the current study are not clear. One possibility is that the failure of cytokine treatment to adequately restore calf muscle microvasculature may account for the lack of flow reserve improvement (and the presence of tibialis anterior muscle atrophy due to lack of nutrient blood flow) compared to the RSAtreated ligated rabbits. Further, as noted by Cao et al. [19] with FGF-2 and PDGF-BB, there may be an optimal dose ratio between VEGF-B and FGF-2, which was not achieved in this study; this would need to be established in future work.

Bilateral femoral artery ligation caused an increase in the number of angiographically visible collateral arteries at day 14, which was further enhanced by combined treatment with FGF-2 and VEGF-B. In mice, after 28 days of unilateral ischemia, VEGF-B treatment caused a $70-80 \%$ increase in capillary and arteriole vessel/muscle fiber ratios in gastrocnemius muscles (measured by immunohistochemistry), as well as a $40 \%$ greater angiographic score (which probably correlates with collateral vessel remodeling), in ischemic compared to nonischemic hind limbs [5]. FGF-2 administration has also been shown to double capillary/muscle fiber ratio in critically ischemic calf muscles compared to control animals 14 days following femoral artery excision in rabbits [17]. This particular ischemic preparation causes significant muscle atrophy and necrosis, as well as limping and blackened toenails [17]. In rabbits with such severe limb ischemia, Asahara et al. [18] examined the effect of single or combined VEGF-A and FGF-2 treatment administered 10 days after ligation. After 10 days of treatment, there was no difference in stem collateral artery internal diameter between groups; however, by day 30 , combination therapy resulted in a greater (14-23\%) stem collateral artery internal diameter than treatment with either growth factor alone. The number of angiographically visible collateral arteries was similarly improved by each cytokine therapy [18].

The measurement of capillary density in skeletal muscle tissue sections has important limitations, particularly in hind limb ischemia studies. Conventional measures of 
capillary density often rely on examining capillary profiles in transverse section, with capillary density usually expressed as capillary number/muscle section area (capillaries $/ \mathrm{mm}^{2}$ ). If muscle atrophy occurs as a result of ligation (i.e., smaller cross-sectional area), capillary density will appear to increase even when numbers remain unchanged, giving an 'apparent', but not a 'real', increase in total capillary number. Others $[4,17,35]$ have expressed their data as capillary/muscle fiber ratio, so that capillary density is not overestimated due to muscle atrophy. However, a change in muscle fiber number associated with treatment could similarly confound estimations of changes in capillary numbers. This study used the fractionator method for stereological analysis of capillary number described by Gundersen [25]. This is based on sampling a known fraction of an entire muscle section. The advantage of this technique is that capillary profile number can be estimated independently of all other changes in muscle structure or size that might follow ligation [24].

The presence of dominant collateral arteries in the thigh region in this study 14 days after ligation is presumed to have maintained adequate levels of perfusion to the thigh region and so prevented any atrophy in the rectus femoris muscle. Previous studies have demonstrated that, in contrast, the ischemic lower limb is not as well perfused [32, 36, 37]. This could explain the significant tibialis anterior muscle atrophy observed after ligation in this study. Our careful analysis of the capillary number and muscle fiber number, taking account of the fractionator method, showed clearly that VEGF-B alone or in combination with FGF-2 stimulated angiogenesis by day 14 and an increase in muscle fiber, effects not seen with FGF-2 alone. It is unlikely that VEGF-B stimulated the muscle fiber first and then the capillary growth followed, as VEGF-B is well known to specifically stimulate VEGFR-1. Signaling through this specific receptor promotes endothelial cell differentiation into vascular tubes by stimulating NO release via the endothelial NO synthase and Akt proangiogenic pathways [5]. This effect can occur in a Matrigel plug devoid of skeletal muscle cells indicating that the prime action of VEGF-B is to promote endothelial cell migration and proliferation [5]. Therefore, our finding of muscle fiber increase with VEGF-B is probably secondary to the increase in capillary density and thus nutrition.

In contrast, in rabbits with severe hind limb ischemia, capillary/muscle fiber ratio was $40 \%$ enhanced in adductor and semimembranosus thigh muscles compared to the control group 30 days following VEGF-A or FGF-2 administration, while combination therapy caused a doubling in the ratio [18]. Similarly, Kondoh et al. [38] found a $65 \%$ increase in capillary density (measured per 100 muscle fibers) in semimembranosus muscle following VEGF-A and FGF-2 gene transfer, with no further difference observed with combination therapy. However, muscle diameter was not recorded in either of these studies, and loss of muscle fibers could have resulted in a change in capillary/muscle fiber ratio. The lack of enhanced capillarity in our study may reflect the fact that the sampled muscles, particularly from the thigh area (i.e., rectus femoris), were relatively well perfused by collateral vessels in the region, particularly as the model of femoral artery ligation was not as severe as the excision preparation used in other work. Previous studies in rabbits have demonstrated that angiogenesis (measured as capillaries $/ \mathrm{mm}^{2}$ ) occurs in the ischemic lower limb where the greatest perfusion deficit occurs and not in the thigh region [32, 39].

In conclusion, the combination of the growth factors FGF-2 and VEGF-B that target different vascular cells (smooth muscle and endothelial cells or endothelial cells alone, respectively) offers some advantage over either treatment alone, especially in collateral artery development following hind limb ischemia. Angiogenesis, as predicted from the more receptor-specific protein VEGF-B, was demonstrated in this preparation and probably helped to restore much of the perfusion deficit.

\section{Acknowledgments}

The authors would like to thank Ms. Linda Cornthwaite-Duncan and Mrs. Kirsten Messick for research assistance in X-ray angiography and Dr. Andrew Nash (Zenyth Therapeutics, Melbourne, Australia) for supplying the cytokines used in this study.

References $>_{1}$ Rissanen TT, Vajanto I, Ylä-Herttuala S: Gene therapy for therapeutic angiogenesis in critically ischaemic lower limb - on the way to the clinic. Eur J Clin Invest 2001;31:651666 .

2 Tammela T, Enholm B, Alitalo K, Paavonen $\mathrm{K}$ : The biology of vascular endothelial growth factors. Cardiovasc Res 2005;65: 550-563.

3 Takeshita S, Zheng LP, Brogi E, Kearney M, Pu LQ, Bunting S, Ferrara N, Symes JF, Isner JM: Therapeutic angiogenesis. A single intraarterial bolus of vascular endothelial growth factor augments revascularization in a rabbit ischemic hind limb model. J Clin Invest 1994;93:662-670. 
-4 Baffour R, Garb JL, Kaufman J, Berman J, Rhee SW, Norris MA, Friedmann P: Angiogenic therapy for the chronically ischemic lower limb in a rabbit model. J Surg Res 2000; 93:219-229.

5 Silvestre JS, Tamarat R, Ebrahimian TG, LeRoux A, Clergue M, Emmanuel F, Duriez M, Schwartz B, Branellec D, Lévy BI: Vascular endothelial growth factor-B promotes in vivo angiogenesis. Circ Res 2003;93:114123.

6 Srivastava S, Terjung RL, Yang HT: Basic fibroblast growth factor increases collateral blood flow in spontaneously hypertensive rats. Am J Physiol Heart Circ Physiol 2003; 285:H1190-H1197.

7 Voskuil M, van Royen N, Hoefer IE, Seidler R, Guth BD, Bode C, Schaper W, Piek JJ, Buschmann IR: Modulation of collateral artery growth in a porcine hindlimb ligation model using MCP-1. Am J Physiol Heart Circ Physiol 2003;284:H1422-H1428.

-8 Isner JM, Pieczek A, Schainfeld R, Blair R, Haley L, Asahara T, Rosenfield K, Razvi S, Walsh K, Symes JF: Clinical evidence of angiogenesis after arterial gene transfer of phVEGF165 in patient with ischaemic limb. Lancet 1996;348:370-374.

-9 Baumgartner I, Pieczek A, Manor O, Blair R, Kearney M, Walsh K, Isner JM: Constitutive expression of phVEGF165 after intramuscular gene transfer promotes collateral vessel development in patients with critical limb ischemia. Circulation 1998;97:1114-1123.

10 Lazarous DF, Unger EF, Epstein SE, Stine A, Arevalo JL, Chew EY, Quyyumi AA: Basic fibroblast growth factor in patients with intermittent claudication: results of a phase I trial. J Am Coll Cardiol 2000;36:1239-1244.

-11 Kusumanto YH, van Weel V, Mulder NH, Smit AJ, van den Dungen JJ, Hooymans JM, Sluiter WJ, Tio RA, Quax PH, Gans RO, Dullaart RP, Hospers GA: Treatment with intramuscular vascular endothelial growth factor gene compared with placebo for patients with diabetes mellitus and critical limb ischemia: a double-blind randomized trial. Hum Gene Ther 2006;17:683-691.

-12 Walder CE, Errett CJ, Bunting S, Lindquist P, Ogez JR, Heinsohn HG, Ferrara N, Thomas GR: Vascular endothelial growth factor augments muscle blood flow and function in a rabbit model of chronic hindlimb ischemia. J Cardiovasc Pharmacol 1996;27:9198.

-13 Bellomo D, Headrick JP, Silins GU, Paterson CA, Thomas PS, Gartside M, Mould A, Cahill MM, Tonks ID, Grimmond SM, Townson S, Wells C, Little M, Cummings MC, Hayward NK, Kay GF: Mice lacking the vascular endothelial growth factor-B gene (Vegfb) have smaller hearts, dysfunctional coronary vasculature, and impaired recovery from cardiac ischemia. Circ Res 2000;86: E29-E35.
14 Wright CE: Effects of vascular endothelial growth factor (VEGF)A and VEGFB gene transfer on vascular reserve in a conscious rabbit hindlimb ischaemia model. Clin Exp Pharmacol Physiol 2002;29:1035-1039.

15 Mould AW, Greco SA, Cahill MM, Tonks ID, Bellomo D, Patterson C, Zournazi A, Nash A, Scotney P, Hayward NK, Kay GF: Transgenic overexpression of vascular endothelial growth factor-B isoforms by endothelial cells potentiates postnatal vessel growth in vivo and in vitro. Circ Res 2005;97:e60-e70.

16 Nash AD, Baca M, Wright C, Scotney PD: The biology of vascular endothelial growth factor-B (VEGF-B). Pulm Pharmacol Ther 2006;19:61-69.

17 Baffour R, Berman J, Garb JL, Rhee SW, Kaufman J, Friedmann P: Enhanced angiogenesis and growth of collaterals by in vivo administration of recombinant basic fibroblast growth factor in a rabbit model of acute lower limb ischemia: dose-response effect of basic fibroblast growth factor. J Vasc Surg 1992;16:181-191.

18 Asahara T, Bauters C, Zheng LP, Takeshita S, Bunting S, Ferrara N, Symes JF, Isner JM: Synergistic effect of vascular endothelial growth factor and basic fibroblast growth factor on angiogenesis in vivo. Circulation 1995;92(9 suppl):II365-II371.

19 Cao R, Bråkenhielm E, Pawliuk R, Wariaro D, Post MJ, Wahlberg E, Leboulch P, Cao Y: Angiogenic synergism, vascular stability and improvement of hind-limb ischemia by a combination of PDGF-BB and FGF-2. Nat Med 2003;9:604-613.

20 Wright CE, Angus JA: Techniques to measure pharmacodynamics in the intact vasculature. J Pharmacol Toxicol Methods 2000; 44:385-394.

21 Wafai R, Angus JA, Wright CE: Adaptation of hindquarter vascular reactivity to femoral artery ligation and hypercholesterolemia in the rabbit. J Vasc Res 2008;45:279-294.

22 Rees MJ, Taylor GI: A simplified lead oxide cadaver injection technique. Plast Reconstr Surg 1986;77:141-145.

-23 Hoefer IE, van Royen N, Buschmann IR, Piek JJ, Schaper W: Time course of arteriogenesis following femoral artery occlusion in the rabbit. Cardiovasc Res 2001;49:609-617.

24 Bertram JF: Analyzing renal glomeruli with the new stereology. Int Rev Cytol 1995;161: $111-172$.

25 Gundersen HJ: Stereology of arbitrary particles. A review of unbiased number and size estimators and the presentation of some new ones, in memory of William R. Thompson. J Microsc 1986;143(Pt 1):3-45.

26 Wright CE, Angus JA, Korner PI: Vascular amplifier properties in renovascular hypertension in conscious rabbits. Hindquarter responses to constrictor and dilator stimuli. Hypertension 1987;9:122-131.
27 Ludbrook J: Repeated measurements and multiple comparisons in cardiovascular research. Cardiovasc Res 1994;28:303-311.

28 van Royen N, Piek JJ, Buschmann IR, Hoefer IE, Voskuil M, Schaper W: Stimulation of arteriogenesis: a new concept for the treatment of arterial occlusive disease. Cardiovasc Res 2001;49:543-553.

29 Enholm B, Paavonen K, Ristimäki A, Kumar V, Gunji Y, Klefstrom J, Kivinen L, Laiho M, Olofsson B, Joukov V, Eriksson U, Alitalo K: Comparison of VEGF, VEGF-B, VEGF-C and Ang-1 mRNA regulation by serum, growth factors, oncoproteins and hypoxia. Oncogene 1997;14:2475-2483.

-30 Carmeliet P: Mechanisms of angiogenesis and arteriogenesis. Nat Med 2000;6:389395.

-31 Deindl E, Hoefer IE, Fernandez B, Barancik M, Heil M, Strniskova M, Schaper W: Involvement of the fibroblast growth factor system in adaptive and chemokine-induced arteriogenesis. Circ Res 2003;92:561-568.

-32 Ito WD, Arras M, Scholz D, Winkler B, Htun P, Schaper W: Angiogenesis but not collateral growth is associated with ischemia after femoral artery occlusion. Am J Physiol 1997; 273:H1255-H1265.

33 Hershey JC, Baskin EP, Glass JD, Hartman HA, Gilberto DB, Rogers IT, Cook JJ: Revascularization in the rabbit hindlimb: dissociation between capillary sprouting and arteriogenesis. Cardiovasc Res 2001;49:618625.

34 Allen LA, Terjung RL, Yang HT: Exogenous basic fibroblast growth factor increases collateral blood flow in female rats with femoral artery occlusion. J Cardiovasc Pharmacol 2006;47:146-154.

>35 Shyu KG, Chang H, Isner JM: Synergistic effect of angiopoietin-1 and vascular endothelial growth factor on neoangiogenesis in hypercholesterolemic rabbit model with acute hindlimb ischemia. Life Sci 2003;73:563579.

-36 Scholz D, Ito W, Fleming I, Deindl E, Sauer A, Wiesnet M, Busse R, Schaper J, Schaper W: Ultrastructure and molecular histology of rabbit hind-limb collateral artery growth (arteriogenesis). Virchows Arch 2000;436: 257-270.

37 Schaper W, Scholz D: Factors regulating arteriogenesis. Arterioscler Thromb Vasc Biol 2003;23:1143-1151.

38 Kondoh K, Koyama H, Miyata T, Takato T, Hamada H, Shigematsu H: Conduction performance of collateral vessels induced by vascular endothelial growth factor or basic fibroblast growth factor. Cardiovasc Res 2004;61:132-142.

39 Arras M, Ito WD, Scholz D, Winkler B, Schaper J, Schaper W: Monocyte activation in angiogenesis and collateral growth in the rabbit hindlimb. J Clin Invest 1998;101:4050. 